\title{
Simple clinical and bedside urodynamic evaluation is sufficient for successful management decisions in spina bifida patients with urinary incontinence and the machine urodynamics are not necessary
}

\author{
Anant Bangar* and Santosh Karmarkar
}

Address: 11 a, Aradhana, G D Ambedkar Marg, Dadar (east), Mumbai 400014, India

Email: Anant Bangar* - dr.anant.bangar@gmail.com

* Corresponding author

from $\left.5\right|^{\text {st }}$ Annual Meeting of the Society for Research into Hydrocephalus and Spina Bifida Heidelberg, Germany. 27-30 June 2007

Published: 20 December 2007

Cerebrospinal Fluid Research 2007, 4(SuppI I):S2I doi:I0.II86/I743-8454-4-SI-S2 I

This abstract is available from: http://www.cerebrospinalfluidresearch.com/content/4/SI/S2 I

(c) 2007 Bangar and Karmarkar; licensee BioMed Central Ltd.

\section{Background}

Our experience with evaluation of spina bifida with urinary incontinence has evolved through three phases. In the first phase, before the year 2000 we were doing only machine urodynamics. In the second phase with machine urodynamics from (2000 to 2003), we took study to compare the observations and results of simple clinical bedside evaluation (SCBE) in taking management decisions in patients with spina bifida and urinary incontinence. In the third phase, from 2004 onwards, we have stopped doing machine urodynamics completely in evaluation of patients and now do only SCBE. We believe that SCBE is sufficient to take management decisions in such patients. In this paper we will present data of 10 patients of spina bifida whose management decisions were made using SCBE.

\section{Materials and methods}

In the past three years ten patients of spina bifida (age limit 1.5-16 yrs) were treated for their urinary incontinence. All of them were evaluated by SCBE (resting pressure, random residual volume, leak point pressure, bladder capacity, MCU, USG). Based on the results of these tests, management strategies were decided. The case histories, treatments given and outcome (after six months to one year follow up) of these ten patients will be presented and discussed.

\section{Results}

These ten patients have shown significant clinical improvement in continence, which was further ascertained by improvement in findings by SCBE.

\section{Conclusion}

Thus, we strongly believe that SCBE is sufficient for successful management decisions in urinary incontinence and cumbersome and expensive machine urodynamics are unnecessary and need not be performed as routine in these cases. 